\title{
LUT
}

University

\section{Levelized Function Cost: Economic Consideration for Design Concept Evaluation}

\author{
Kozlova Mariia, Chechurin Leonid, Efimov-Soini Nikolai
}

This is a Final draft version of a publication

published by Palgrave Macmillan, Cham

in Chechurin L., Collan M. (eds) Advances in Systematic Creativity. Palgrave Macmillan, Cham

DOI: $10.1007 / 978-3-319-78075-7 \_16$

Copyright of the original publication: (c) The Author(s) 2019

Please cite the publication as follows:

Kozlova M., Chechurin L., Efimov-Soini N. (2019) Levelized Function Cost: Economic Consideration for Design Concept Evaluation. In: Chechurin L., Collan M. (eds) Advances in Systematic Creativity. Palgrave Macmillan, Cham 


\title{
Levelized function cost:
}

\section{economic consideration for design concept evaluation}

\author{
Mariia Kozlova, Leonid Chechurin, Nikolai Efimov-Soini \\ Lappeenranta University of Technology, School of Business and Management
}

\begin{abstract}
Design concept selection lacks economic evaluation in the early stages of the design process. This chapter introduces the levelized function cost for express design evaluation, adapted from the power generation sector. A single indicator represents all concept-related life-cycle costs per a unit of function produced, reflecting also the lifetime and productivity. The indicator allows comparing fundamentally different designs, and handles different sets of function objects. After a brief overview and comparison of potential indicators for economic assessment of design concepts this paper introduces the levelized function cost providing its derivation and definition, analyzes its sensitivity to the input variables, depicts the range of problems that can be addressed with the levelized function cost estimate, and finally illustrates its application in a flow meter design case.
\end{abstract}

Keywords: levelized cost, life-cycle cost, new product design, design assessment, design selection.

\section{Introduction}

The ability to produce innovations systematically is rewarding. The design of a tangible, especially technology-driven innovation is mostly the design of a product. The latter stage of 
the innovation process has deserved a special title in modern communications, namely new product design (NPD). A typical NPD roadmap encompasses the following stages or milestones: Marketing (analysis of customer needs) $\rightarrow$ Specification (technical requirements for engineering) $\rightarrow$ Conceptual design (idea or the general concept for a new product) $\rightarrow$ Detailed design $\rightarrow$ Manufacture $\rightarrow$ Selling (Pugh and Clausing 1996). Sometimes marketing and selling are not needed or are performed in a reduced form (for example, when we develop a product or technology for our own needs).

Conceptual design is an important but a vulnerable stage of the life cycle of a new product/technology. It is important because the price of a good idea can be very high. Once the concept has been selected, detailed design will start. The closer the design to its end, the higher the price of the changes, especially at the conceptual level.

On one hand, ideation is very important for NPD, on the other, this design process stage is the least documented, standardized and supported by methods. There are tools to stimulate brain activity in general (lateral thinking, brainstorming, synectics etc.) and tools that provide systematic design problem analysis and synthesis or concept generating (e.g. morphological analysis, axiomatic design, design for manufacturing and assembly, and theory for inventive problem solving (TRIZ)). The latter group can be also tagged as artificial intelligence methods, because they teach algorithms to support new concept generation.

In fact, idea generation cannot be separated from idea evaluation. Separating the ideation phase from the evaluation phase will result in big losses: every design idea that does not make it through the evaluation gate wastes both efforts. The most typical evaluation gates for engineering are the following: Does the design contradict physical laws? Is the design manufacturable (especially for mass production)? Is the design economically viable? (Wallace and Burgess 1995, 429-446). We will not discuss patent and licensing issues here. The drama is that in big technology-driven business these questions are answered by different people. Although engineering designers are aware of the basic costs of the design, the detailed 
estimation of the profits is performed by economists. Ideally, the concept generation process goes hand in hand with evaluation and decision-making.

Interestingly, some systematic creativity methods assist solely idea generation (morphological box), some provide certain, although non-economic evaluation criteria to tell good design apart from bad design (axiomatic design), and some toolkits, like TRIZ, contain both instruments. The theory for inventive problem solving seems to be exceptionally general and powerful compared to other theories. The first publication on the method appeared in the mid-1950s in the USSR (Altshuller and Shapiro 1956, 37-49). It was developed by Altshuller and his followers into a set of tools for situation modelling (function modelling, substance-field models, contradictions), formal rules of model transformation (trimming, inventive standards, inventive principles), and the design evaluation axioms (ideal final result, trends for engineering system evolution). There is evidence of wide applications of TRIZ in design practice reported by many innovation leaders (General Electric, Samsung group, Intel, Procter and Gamble etc.) and design engineers (Moehrle 2005, 285-296; Ilevbare, Probert, and Phaal 2013, 30-37). The approach became the subject of scientific publications much later. However, about 1400 research papers in the SCOPUS database have been devoted to TRIZ since 2000 (Chechurin and Borgianni 2016, 119-134). One fundamental difference of TRIZ from other design techniques is the focus shift from design (material objects; components, links etc.) to functions. Thus an ideal system is believed to be a system that does not exist (and therefore does not cost anything) but performs the required function.

The ideality-driven idea evaluation in TRIZ leads to minimalistic design concepts with a minimal amount of components that perform the required function only when necessary and where necessary. The focus on the function provokes the idea that the economic evaluation of the design is to be performed on the function level as well.

Let us consider a concept design stage for a very simple system as an example. We need to design a holder for the whiteboard eraser. An immediate idea would be a plate 
at the bottom of the board, a kind of a shelf. Indeed, a narrow board would be a simple concept with small material, manufacturing and maintenance cost. However, to perform the required function we would need to introduce an element (a board). Alternatively, the issue can be addressed with the concept of the ideal final result, which states that the "ideal" system is no system at all, but the ensured function. Even more, the function is ensured only when it is necessary (when the eraser exists and we do not use it) and where it is necessary (where we realize that the eraser is not needed any more). To embody this model we can teach the eraser to hold itself somewhere on the board. It could be realized with the help of several physical phenomena: (i) magnetizing the eraser or a part of it, (ii) giving the eraser a static charge, or (iii) making the surface of the eraser porous or sticky etc. In this concept the "shelf" is ideal (according to the TRIZ concept), it (almost) does not exist, requires zero material, but the eraser can be held.

When alternative conceptual designs are ready, it needs to be selected which of them to develop further. All three trade-offs represent the ideal final result (in terms of TRIZ) from the engineering point of view. However, their expected economic viability can differ a lot and must be considered at an early stage of NPD. Any cost-benefit analysis would stumble on the estimation of revenue from holding the eraser. Such attempts would complicate evaluation and open the door for manipulation with the results. This problem requires an indicator that is simple, clear and not too demanding for calculation that focuses on the function performed in order to provide engineers with a tool to compare and make a choice between the alternative concepts from the economic point of view.

Some researchers have revealed possible psychological biases in the decision-making within the design selection process (Dong, Lovallo, and Mounarath 2015, 37-58; Nikander, Liikkanen, and Laakso 2014, 473-499; Toh and Miller 2015, 111-138). Although a broad set of methods 
exists to assist the selection process (Okudan and Tauhid 2008, 243-277), only a few incorporate economic viability.

The classical technique to estimate the profitability of any project, investment analysis (referred to as the capital budgeting in the finance literature) (Ryan and Ryan 2002, 355-364), implies estimating future benefits and costs, and offers some profitability indicators. However, such analysis requires more or less detailed estimates of future cash flows, which can be intricate regarding the benefit side of some design functions, such as e.g. metering. Moreover, investment analysis is a demanding process that often requires expertise of specialists from different fields. These facts impede the application of investment analysis in design evaluation. A modified measure for investment profitability, equivalent annual annuity or cost, allows comparing alternatives with different lifetime, but does not, however, solve the other abovementioned disadvantages connected with investment analysis and estimating future project cash-flows.

A wide literature review conducted by Okudan and Tauhid (2008, 243-277) classifies a variety of concept selection methods. Among those classes are multi criteria decision making methods (MCDM), decision matrices, optimization based methods etc. The only method profoundly accounting economic assessment is utility theory-based models. However, manual assigning of 'utility scores' to design attributes would not necessarily reflect the actual profitability of a design.

In practice, the Value Engineering (VE) approach (Miles and Boehm 1967) is often used to manage the cost-benefit ratio of a design, embedded into some international (e.g. ISO 9000) and corporate standards (SAVE International 2015). However, it is a complex approach and represents rather a management system than a valuation technique. It consists of a set of practical principles for quality management, but does not provide any particular solution for economic assessment. 
Some researchers have incorporated market factor consideration into design valuation to reflect possible adoption success of a new product (Besharati, Azarm, and Kannan 2006, 333-350; Park and Park 2004, 387-394; Malen 1996, 105-122), however, required assumptions can be difficult to make on the early stages of design development.

Thus, the conceptual design stage, where the decisions are the most critical and costly, is left without a reliable economic indicator that would navigate the selection of ideas, successful not only technically, but economically as well.

Inspired by the practice of using a single simple indicator in the energy industry, we suggest paying attention to the levelized cost concept. It is widely used in the energy sector, where it is known as the levelized cost of electricity (LCOE). LCOE is a relative indicator that aggregates all project-related costs per unit of electricity produced (by a particular project over its lifetime). The different technology types in the energy sector may differ substantially by capital and operating costs, lifetime, electricity production performance, etc. LCOE reflects all these features in one figure, and enables thus comparison of different technologies. In addition, it is convenient to display trends of technology development in time and analyze its overall learning curve. LCOE has become a common indicator in the energy industry analysis, used actively by both business (see e.g. (US Energy Information Administration 2015; World Energy Council 2013; Bloomberg New Energy Finance 2015), and academia (see e.g. (Branker, Pathak, and Pearce 2011, 4470-4482; Campbell et al. 2008; Breyer and Gerlach 2013, 121-136; Ouyang and Lin 2014, 64-73; Hernández-Moro and Martínez-Duart 2013, 119-132).

Being essential in the power sector, the levelized cost concept has not conquered other industries yet, but limited application examples have been presented by e.g. (Ogden et al. 1996, 115-130; Khastagir and Jayasuriya 2011, 3769-3784). However, its applicability in the valuation of any products or services has been shown by Reichelstein and Rohlfing (2014). In particular, they show that levelized cost as a single aggregated indicator is a feasible economic measure of planned investment. 
Essential for the power generation sector, the function-orientation makes LCOE convenient for design evaluation with a focus on its function. Therefore, in this paper we generalize levelized cost of energy to levelized function cost (LFC).

Similar to the LCOE concept idea, life-cycle cost analysis is implemented in some industries to support the decision-making (Fuller and Petersen 1995), for example the British Standard BS ISO 15686-5:2008 for building and construction assets, as well as it is suggested to complement VE (Younker 2003). However, life-cycle cost only accounts for project costs, but not for its function leaving such parameters as its productivity and lifetime beyond the evaluation scope. We claim that the LFC concept can be utilized to assist decision-making in the engineering design choice. We continue with overview and comparison of several potential indicators for economic appraisal of design concepts, showing relative advantages of the levelized function cost. Before switching to a detailed explanation of the levelized function cost formula, we first present the definition of function. Several generic examples serve to demonstrate the usefulness of the LFC estimate for different types of problems. With a numerical example of flowmeter design types we illustrate how the levelized cost concept can provide insights into expected economic success of different design concepts.

\section{Overview of selected indicators for economic appraisal of design concepts}

A traditional, well-known and broadly used profitability indicator for economic appraisal of any investment is Net Present Value (NPV) (Ryan and Ryan 2002, 355-364; Graham and Harvey 2001, 187-243). Its rise dates to times of Karl Marx (1894) and Irving Fisher (1907). It represents the sum of all project-related cash flows, discounted to properly account for the time value of money. (There are also such indicators as internal rate of return and profitability index, but similar to NPV they are based on the discounted cash flow notion so we leave them outside of the scope of this comparison.) NPV is often used to assess investment projects, though for smaller capital investments like separate technical devices the Equivalent Annual Annuity (EAA) approach is shown as more suitable (Jones and Smith 1982, 103-110). It converts NPV 
to equivalent annuity payments. This allows comparing projects with different lifespans that is not applicable with NPV. However, when considering such technical devices embedded into a bigger system, estimation of revenues can be complicated and leaves a room for manipulation with results. Perhaps because of that, Value Engineering concept adapts the life-cycle cost (LCC) estimate, an NPV analog, but without revenue consideration (Younker 2003). It represents all design-related costs, including its initial cost (e.g. manufacturing and installation costs), operating and maintenance cost occurred over the whole lifetime and disposal cost if any. Nevertheless, excluding cash inflows from the calculation, a new drawback arises, namely, inability of LCC to capture possibly different production profiles of estimated alternatives. Keeping advantage of excluded from the estimation revenues, this drawback can be solved by introducing costs weighted per production unit, which is reflected in the levelized cost of energy indicator, widely used in the power production field (Short, Packey, and Holt 2005). The formulation of each indicator and the summary of their advantages and disadvantages are given in Table 1.

Table 1. Comparison of selected indicators for design evaluation

\begin{tabular}{|c|c|c|c|c|}
\hline & $\begin{array}{c}\text { NPV } \\
\text { net present value }\end{array}$ & $\begin{array}{c}\text { EAA } \\
\text { equivalent } \\
\text { annual annuity }\end{array}$ & $\begin{array}{c}\text { LCC } \\
\text { life-cycle cost }\end{array}$ & $\begin{array}{c}\text { LCOE } \\
\text { levelized } \\
\text { cost of } \\
\text { energy }\end{array}$ \\
\hline $\begin{array}{l}\text { General } \\
\text { formula } \\
\text { where } n \text { is time } \\
\text { period, } N \text { is total } \\
\text { number of time } \\
\text { periods in lifetime, } I \\
\text { is initial cost, Rev is } \\
\text { revenues, } O \& M \text { is } \\
\text { operating an } \\
\text { maintenance costs, } d \\
\text { is discount rate, and } \\
C R F \text { is a capital } \\
\text { recovery factor. } \\
\text { (I and O\&M are } \\
\text { negative and Rev is } \\
\text { positive) }\end{array}$ & $N P V=\sum_{n=0}^{N} \frac{I+(\operatorname{Rev}+O \& M)_{n}}{(1+d)^{t}}$ & $E A A=N P V * C R F$ & $L C C=\sum_{n=0}^{N} \frac{I+O \& M_{n}}{(1+d)^{n}}$ & $\begin{array}{c}L C O E \\
=\frac{\sum_{n=0}^{N} \frac{(I+O \& M n}{(1+d) n^{n}}}{\sum_{n=0}^{N} \frac{Q_{n}}{(1+d)^{n}}}\end{array}$ \\
\hline
\end{tabular}




\begin{tabular}{|l|c|c|c|c|}
\hline $\begin{array}{l}\text { Formula (equal } \\
\text { CF over time) }\end{array}$ & $N P V=I+\frac{(R e v-O \& M)_{a}}{C R F}$ & $\begin{array}{l}E A A \\
=I * C R F \\
+(R e v-O \& M)_{a}\end{array}$ & $\begin{array}{l}L C C \\
=I * C R F+O \& M_{a}\end{array}$ & $\begin{array}{l}L C O E \\
=\frac{I * C R F+O \& M_{a}}{Q_{a}}\end{array}$ \\
\hline $\begin{array}{l}\text { Comparable for } \\
\text { different } \\
\text { lifetime }\end{array}$ & NO & YES & NO & YES \\
\hline $\begin{array}{l}\text { No need to } \\
\text { estimate } \\
\text { revenues }\end{array}$ & NO & NO & YES & YES \\
\hline $\begin{array}{l}\text { Comparable for } \\
\text { different } \\
\text { productivity }\end{array}$ & YES & YES & NO & YES \\
\hline
\end{tabular}

The table contains the general formula of the indicator, its simplified form, when annual cash flows (and production) are constant over time, and analysis of such advantages as comparability for different lifetime, absence of necessity to estimate revenues, and comparability for different productivity.

One can see that LCOE is the only indicator that possesses all mentioned features being able to tackle design concepts with different lifetime and productivity simultaneously not requiring estimating revenues. However, whereas electricity production is an unambiguous measurable output, definition of design function requires some further clarification.

\section{Definition of function}

The primary goal of any engineering design efforts (in contrast to artistic design in general) is to ensure certain demand for function. Something does not happen itself, naturally, and therefore we order to engineer an artificial device that performs the required function. Having ensured the specified function of the system we can think of other important features of the product: cost, quality, sustainability etc. There are special tools or design management approaches to address all the requirements: Product cost analysis or Design-to-Cost (DTC), design for manufacturing and assembly (DFMA), design for quality (DFQ) and many others (Magrab et al. 2009). 
Thus, the design for function is the first and inevitable stage of new system design and therefore how the function is described and how the quantitative specification for function is given are very important for the success. Having based on nothing but engineering folklore the following story is given to provide an understandable illustration. A team of space engineers worked on Lunar vehicle search lamp bulb shell design somewhere in the USSR in 60s of last century. The bulb had to withstand substantial landing accelerations. The main function of the bulb shell was defined as "to protect the tungsten filament" that sits inside the bulb and emits the light. Certain design efforts were spent to develop such a glass shell and bound it reliably to the metal bulb base. When someone reformulated the function requirements for the shell "to stop the oxygen" or "to maintain the vacuum" suddenly the designers realized that there is no need for the shell at all: there is no oxygen on the Moon or, in other words, there is perfect vacuum there.

This significant simplification of design originated from careful function definition was given a systematic treatment in a school of thought named TRIZ (the theory for inventive problem solving, first publication (Altshuller and Shapiro 1956, 37-49)). The first principles of "correct" function formulation can be found in the concept of Ideal final result (IFR) and the model of an engineering system in classical TRIZ. A bit later these principles took a form of extended roadmap for the inventive design based of function analysis called Function-cost analysis (first publication is S.Litvin et all, 1984, in Russian). Function analysis and tools for modification of design based on it, form the modern TRIZ school. In essence, the approach helps to get rid of function chimeras and declarative functions in new system specification, that can substantially simplify the design. Other remarkable tool for formal function based analysis for engineering system is the method standardized by National institute of standards, USA (Hirtz et al. 2001). The approach suggests a list of standard functions that are typically required from engineering system. A popular function based design tool is Axiomatic design (AD) (Suh 1990), that guides through the function requirements decomposition and linking them to design parameters, see also in textbook (Magrab et al. 2009). 
The main difference in those approaches is how the function is defined. The set of functions is large and can include field specific or declarative function expressed in almost natural (common sense) language in NIST approach or AD. While TRIZ-based approach requires careful analysis before the function formulation becomes formally legitimate. In fact, the list of legitimate functions hardly exceeds 5 verbs. Thus, functions like "to protect" or "to measure" can be easily met in AD or NIST and never in TRIZ-based function models.

Thus, the function analysis of TRIZ suggests a simple language or set of functions for the description of an engineering system. It is so simple that it can be called modelling. A complex products can be decomposed in a set of units and the same way the main function (or a function for which the product has been designed for) can be decomposed into the elementary functions from a set of legitimate ones. If multiple function requirements are exposed to the design, it should be considered one by one or in the same function model. (A kettle is to heat the water and to hold the water. Thus we should either build two function models for functions "heat" and "hold" or to have one function model where the flow of functions show how the kettle's components contribute to perform those two function requirements). It is important to acknowledge another benefit of TRIZ based function modelling: these functions are very simple and measurable by definition. The latter concludes this subsection and is supposed to be used in the remainder of the paper.

The function is legitimate if

- there are two material objects (or fields): function carrier and function recipient;

- they interact directly;

- there is a parameter of function recipient that has been changed or maintained due the function.t

A reader can experiment with these definition revealing that common sense models "casing protects the chip" or "the thermometer measures the temperature" are not legitimate any more (Gerasimov et al. 1991, 40). 


\section{Levelized function cost for design valuation}

This section introduces the concept of levelized function cost. The rationale behind it is simple and straightforward: LFC is all design (or project) -related costs per a unit of the total function output, properly adjusted for the time value of money. We start with the derivation of LFC arriving in its definition. Further, we show how the different features of a design influence the resulting LFC estimate, and based on it, we reveal when using LFC is relevant. The section ends with several generic examples illustrating the applicability of the LFC estimation.

\subsection{Definition and derivation of levelized function cost}

Levelized cost (of electricity or any other function unit) can be defined as a price level that covers exactly all project or design costs

$$
T L C C=\sum_{n=0}^{N} \frac{Q_{n} * L F C}{(1+d)^{n}},
$$

where

$T L C C$ is the total lifecycle cost,

$Q_{n}$ is the (electricity) output or productivity,

$d$ is discount rate,

$n$ is period index, and

revenue $Q^{*} L F C$ is discounted to account for the time value of money.

The total lifecycle cost is simply the sum of all discounted project costs

$$
T L C C=\sum_{n=0}^{N} \frac{C_{n}}{(1+d)^{n}}
$$

where

$C_{n}$ is annual costs, including initial investment and operating expenses.

Combining equations (1) and (2) gives (3), 


$$
\sum_{n=0}^{N} \frac{Q_{n} * L F C}{(1+d)^{n}}=\sum_{n=1}^{N} \frac{C_{n}}{(1+d)^{n}}
$$

from which we arrive at the general definition of LFC (7).

\section{Definition 1}

Levelized function cost is a single indicator that shows the price level of a unit of function produced that would cover all costs related to the usage of a design, including initial manufacturing and installation, as well as operation and maintenance costs, properly accounted for a time value of money

$$
L F C=\frac{\sum_{n=0}^{N} \frac{C_{n}}{(1+d)^{n}}}{\sum_{n=0}^{N} \frac{Q n}{(1+d)^{n}}} .
$$

If the initial costs occur within the base period $n=0$, then (4) can be rewritten as follows

$$
L F C=\frac{I+P V(O \& M)}{\sum_{n=0}^{N} \frac{Q n}{(1+d)^{n}}}
$$

where

$I$ is the total initial cost of a design (device), including its manufacturing and installation, and $P V(O \& M)$ are discounted operation and maintenance costs through the service life.

Formula (5) simplifies the situation to a 'no taxes' environment that is suitable when assessing small elements of the total business. For other options see details in (Short, Packey, and Holt 2005).

LFC calculation can be simplified if the annual output $Q$ and/or $O \& M$ costs are constant over time:

- If $Q$ is equal over time, 


$$
L F C=\frac{I+P V(O \& M)}{Q_{a} / C R F}=\frac{I+P V(O \& M)}{Q_{a}} * C R F
$$

where

$Q_{a}$ is an annual function output, and

$C R F$ is the capital recovery factor $\frac{d(1+d)^{N}}{(1+d)^{N}-1}$ defined by discount rate $d$ and the total number of periods (years) of the design/project service life $N$.

- If $Q$ and $O \& M$ costs are equal over time,

$$
L F C=\frac{I+\frac{O \& M_{a}}{C R F}}{Q_{a}} * C R F=\frac{I * C R F+O \& M_{a}}{Q_{a}},
$$

where

$O \& M_{a}$ is the annual operation and maintenance costs.

\section{Definition 2}

If the function output and O\&M costs are equal over time, levelized cost can be defined as the sum of annualized initial costs and annual O\&M costs over the annual function output

$$
L F C=\frac{I * C R F+O \& M_{a}}{Q_{a}}
$$

For the purpose of design valuation, we recommend using the risk-free rate as the discount rate in the LFC formula, or its national equivalent, if the scope of design applicability is limited to one country.

It is important to treat inflation correctly in the calculation differentiating between real and nominal terms. Formulation (8) implies O\&M costs expressed by one figure in real terms (without inflation effect), so the real discount rate should be used to calculate $C R F$. Since the risk-free rate, as any other interest rates, is usually reported in nominal terms, it should be 
converted into the real one. For further details on calculating real and nominal LFC see (Short, Packey, and Holt 2005). Disposal costs must be included in LFC as well, if any occur for the estimated concepts.

In a nutshell, the levelized function cost represents all the life-cycle concept-related costs properly accounted for the time value of money per a unit of function output expected to be produced by the concept. Thus, a higher LFC would signify more expensive solution to performing a particular function and vice versa. Therefore, LFC can be used to compare alternative design concepts.

\subsection{Factors influencing levelized cost}

The simplified formula of levelized cost (8) shows the influence of the contributing factors on the LFC estimate explicitly. It allows performing analytical sensitivity analysis by evaluating partial derivatives.

The sensitivity of LFC to initial and O\&M costs is linear and proportional to annual productivity $(9,10)$

$$
\begin{gathered}
\frac{\partial L F C}{\partial I}=\frac{C R F}{Q_{a}}, \\
\frac{\partial L F C}{\partial O \& M_{a}}=\frac{1}{Q_{a}} .
\end{gathered}
$$

Levelized function cost from annual productivity is a nonlinearly decreasing (11) and convex (12) function, implying that the more productivity, the less marginal LFC there is

$$
\begin{gathered}
\frac{\partial L F C}{\partial Q_{a}}=-\frac{I * C R F+O \& M_{a}}{Q_{a}^{2}}, \\
\frac{\partial^{2} L F C}{\partial Q_{a}^{2}}=\frac{2\left(I * C R F+O \& M_{a}\right)}{Q_{a}^{3}} .
\end{gathered}
$$

The influence of the device lifetime and the discount rate on LFC is also nonlinear $(13,14)$

$$
\frac{\partial L F C}{\partial N}=\frac{\frac{d(d+1)^{N} \log (d+1) I}{(d+1)^{N}-1}-\frac{d(d+1)^{2 N} \log (d+1) I}{\left((d+1)^{N}-1\right)^{2}}}{Q_{a}},
$$




$$
\frac{\partial L F C}{\partial d}=\frac{\frac{d(d+1)^{N-1} I N}{(d+1)^{N-1}}-\frac{d(d+1)^{2 N-1} I N}{\left((d+1)^{N}-1\right)^{2}}+\frac{(d+1)^{N}}{(d+1)^{N}-1}}{Q_{a}} .
$$

The LFC derivative with respect to $N$ is negative, showing the decrease of LFC with increasing the lifetime, while the opposite occurs with respect to the discount rate. The latter reflects the cost of financing the investment and contributes essentially to LFC rise. The second derivatives for both $N$ and $d$ are positive.

Table 2 summarizes the sensitivity of LFC to the variables. Increasing the service life or productivity of a design ceteris paribus would decrease its levelized function cost. The convex character of the function implies that the maximum effect can be achieved with the initial improvement of service life or productivity of the design, but further improvement decreases the marginal benefit from it. Essentially, higher initial or O\&M costs or discount rate would increase the levelized function cost.

Table 2. The effects of variables on LFC

\begin{tabular}{|l|l|l|}
\hline Variable & Component in the LFC formula (8) & Type of function \\
\hline Service life & CRF & decreasing, nonlinear, convex \\
\hline Productivity & $Q$ & \multirow{2}{*}{ increasing, linear } \\
\cline { 1 - 2 } Initial cost & $I$ & \\
\hline O\&M costs & O\&M & increasing, nonlinear, convex \\
\hline Discount rate & $C R F$ & \\
\hline
\end{tabular}

Overall, the type and sign of LFC change with different parameter variations are known. However, sensitivity analysis for each particular case is relevant because of possibly different ranges of values, as well as units of input variables for different problems. 


\subsection{Range of problems that can be tackled with levelized cost}

We have recognized two major types of questions in engineering concept selection that can be addressed with LFC:

A. Which design is cheaper for a particular task?

B. Which design offers more cost reduction in the market?

The first question is relevant in the context of a particular operation that requires a particular function to be performed. In this case, the costs of different design options should be compared directly with each other.

The second question deals with general NPD selection problem, focusing on predicting the success of different designs in the market. In this case, the potential cost savings of an invented design are defined over the current market technology (the difference in the levelized function cost of the existing and the new design) and selects the one that offers more cost reduction.

Levelized cost allows comparing solutions designed for different sets of application objects performing the same function. To illustrate that, let us assume that design $D_{1}$ performs the function for three objects $\{a, b, c\}, D_{2}$ for $\{a, b\}$ and $D_{3}$ for $\{c\}$. Then to define the least-cost solution (question I) the LFC of $D_{1}$ should be compared with the sum of the LFC of $D_{2}$ and $D_{3}$ weighted by the production volume.

$$
\begin{gathered}
D_{1} \rightarrow\{a, b, c\}, D_{2} \rightarrow\{a, b\}, D_{3} \rightarrow\{c\}, \text { then } \\
\operatorname{LC}\left(D_{1}\right) \perp \operatorname{LC}\left(D_{2}\right) w_{2}+\operatorname{LC}\left(D_{3}\right) w_{3},
\end{gathered}
$$

where

$\rightarrow$ stands for to which objects the design performs the function,

$\perp$ is the comparability sign, and

$w_{2}$ and $w_{3}$ are the weights of the respective design production in the total volume. 
When comparing the new design cost with the market benchmark, either a design with the same set of objects should be found, or a logic similar to (15) should be applied, if the same set of objects can be constituted with several existing solutions.

The LFC concept becomes relevant when it is not clear whether a more simple solution from the engineering point of view would deliver more value for the customers. Simplification often limits the applicability of a design to a specific object. Alternatively, a modest increase in complexity can offer some extension of the applicability. LFC provides a rough and quick estimation of such a choice from the economic viability perspective.

Considering the parameters participating in the LFC calculation (see Table 2), it can offer comparison of designs with:

a. Different ratio of O\&M expenses to the initial cost (e.g. the O\&M cost of a design can be reduced to nothing, but it would increase the manufacturing cost);

b. Different service life (e.g. increase in the service life can be achieved only with some increase in manufacturing cost and/or O\&M costs);

c. Different productivity (that would also cause increase in the initial and/or O\&M costs);

d. Different sets of objects of a function (e.g. expanding object coverage with some increase in the cost or loss in service life duration);

e. Any combination of the abovementioned.

The listed scenarios challenge the choice and require an economic viability assessment for solid decision-making.

\subsection{Generic examples}

This section presents a simplified case of design comparison to demonstrate levelized cost in use. We consider all the scenarios presented above, except the last one, which is introduced in a real case illustration in the next section.

a. Different ratio of O\&M expenses to the initial cost 
Let us take as a basis an imaginary design $D_{1}$ that performs a function on object $A_{1}$. Let its initial cost be equal to 10 currency units $(c . u$.), the annual productivity 2 function units at 1 c.u. of O\&M costs, and its lifetime 50 years.

Now let us assume that the same function on the same object can be realized by another design, $D_{2}$, which eliminates O\&M costs totally, but its initial cost would be $50 \%$ higher, other things being equal. The question arises, which of them is cheaper overall.

LFC provides a straightforward answer to this question. Assuming the real risk-free rate at 5\% in (8) we get the following result:

$$
\begin{gathered}
\operatorname{LFC}\left(D_{1}\right)=\frac{10 * \frac{5 \%(1+5 \%)^{50}}{(1+5 \%)^{50}-1}+1}{2}, \operatorname{LFC}\left(D_{2}\right)=\frac{15 * \frac{5 \%(1+5 \%)^{50}}{(1+5 \%)^{50}-1}+0}{2}, \\
\operatorname{LFC}\left(D_{1}\right)=0.77>\operatorname{LFC}\left(D_{2}\right)=0.41
\end{gathered}
$$

With the given assumptions, the second design can provide the same function almost twice cheaper than the first one. However, with other inputs, the result can be the opposite, e.g. if the initial cost is 100 instead of 10 .

b. Different service life Another engineering idea can offer a design $D_{3}$ (for the same function and object) with doubled service life, but it can be achieved only with an $20 \%$ increase in the initial cost.

$$
\begin{gathered}
\operatorname{LFC}\left(D_{1}\right)=\frac{10 * \frac{5 \%(1+5 \%)^{50}}{(1+5 \%)^{50}-1}+1}{2}, \operatorname{LFC}\left(D_{3}\right)=\frac{12 * \frac{5 \%(1+5 \%)^{100}}{(1+5 \%)^{100}-1}+1}{2}, \\
\operatorname{LFC}\left(D_{1}\right)=0.77<\operatorname{LFC}\left(D_{3}\right)=0.80 .
\end{gathered}
$$

Although the idea may seem appealing, the levelized cost estimate shows that it is not economically viable.

c. Different productivity 
Another NPD direction can target the increase in productivity. Alternative design $\mathrm{D}_{4}$ can double the productivity while increasing the O\&M costs by $50 \%$.

$$
\begin{gathered}
\operatorname{LFC}\left(D_{1}\right)=\frac{10 * \frac{5 \%(1+5 \%)^{50}}{(1+5 \%)^{50}-1}+1}{2}, \operatorname{LFC}\left(D_{4}\right)=\frac{10 * \frac{5 \%(1+5 \%)^{50}}{(1+5 \%)^{50}-1}+1.5}{4}, \\
\operatorname{LFC}\left(D_{1}\right)=0.77<\operatorname{LFC}\left(D_{4}\right)=0.51 .
\end{gathered}
$$

The LFC estimate confirms the expediency of such a solution.

d. Different sets of objects of a function

Often one function must be applied to different function recipients (objects). If the issue is to find the lowest cost solution of performing this function within a particular operation or business, it is reasonable to compare whether two different designs specialized on distinct objects are cheaper than the one more sophisticated that can handle the whole set of required objects.

Let us assume that in addition to object $a_{1}$, the same function is required for $a_{2}$. While object $a_{1}$ can be served by $D_{1}$ and $a_{2}$ by $D_{5}$ (with all the same features, except $20 \%$ less initial cost and $50 \%$ higher O\&M costs), both objects can be treated by a more expensive $D_{6}$ with initial cost equal to 10 c.u., the rest being equal.

$$
\begin{gathered}
\left(L F C\left(D_{1}\right)+\operatorname{LFC}\left(D_{5}\right)\right) / 2=\frac{\frac{10 * \frac{5 \%(1+5 \%)^{50}}{(1+5 \%)^{50}+1}+1}{2}+\frac{8 * \frac{5 \%(1+5 \%)^{50}}{(1+5 \%)^{50}-1}+1,5}{2}}{2}, \operatorname{LFC}\left(D_{6}\right)= \\
\frac{12 * \frac{5 \%(1+5 \%)^{50}}{(1+5 \%)^{50}-1}+1}{2}, \\
\left(\operatorname{LFC}\left(D_{1}\right)+\operatorname{LFC}\left(D_{5}\right)\right) / 2=0.87>\operatorname{LFC}\left(D_{6}\right)=0.83 .
\end{gathered}
$$


Since $D_{1}$ and $D_{5}$ have the same productivity, we simply take the average of their LFC to obtain the function cost for both objects (see (15)). The LFC estimate suggests that with the given assumptions, using the more sophisticated design is cheaper.

Different designs can also be compared with respect to potential success in the market. If $D_{1}$ and $D_{6}$ represent the NPD choice, they should be compared to their market analogs that perform the same function for the same set of objects. Assuming the $D_{1}$ analog costs $30 c . u$. and serves for 35 years, and the $D_{6}$ analog costs 20 and serves for 25 years, we can estimate which design would deliver more cost reduction to the market. The chosen values indicate that $D_{1}$ offers a greater cut in the initial cost, but less increase in the service life in comparison with $D_{6}$, but the overall effect is unclear, however.

$$
\begin{gathered}
1-\frac{\operatorname{LFC}\left(D_{1}\right)}{\operatorname{LFC}\left(D_{1}\right)}, 1-\frac{\operatorname{LFC}\left(D_{6}\right)}{\operatorname{LFC}\left(D_{6}\right)}, \\
1-\frac{\frac{1}{2}\left(10 * \frac{5 \%(1+5 \%)^{50}}{(1+5 \%)^{50}-1}+1\right)}{\frac{1}{2}\left(30 * \frac{5 \%(1+5 \%)^{35}}{(1+5 \%)^{35}-1}+1\right)}, 1-\frac{\frac{1}{2}\left(12 * \frac{5 \%(1+5 \%)^{50}}{(1+5 \%)^{50}-1}+1\right)}{\frac{1}{2}\left(20 * \frac{5 \%(1+5 \%)^{25}}{(1+5 \%)^{25}-1}+1\right)},
\end{gathered}
$$

$$
45 \%>31 \% \text {. }
$$

According to this example, the first design $D_{1}$ offers more relative cost reduction per unit of function than $D_{6}$, implying the decision to be in favor of $D_{1}$. In spite of the fact that these designs have different function recipients, they become comparable with the LFC estimate.

Overall, the levelized cost estimate can be used to evaluate and compare different designs with different features against each other or against market benchmarks. As it represents a relative indicator of the overall costs per unit of performed function, it can be applied to any conceptual product or service with defined functionality. 


\section{Case illustration}

Below, we illustrate the problem of design concept choice and the application of LFC for making economy-wise decision with a case of flowmeters. The necessity of flow measurement of a liquid or a gas arises in a number of different fields, including water management, the energy sector, mining, food processing, agriculture etc. The different concepts of flowmeter design are based on different physical phenomena. We focus on three of them, namely, turbine, electromagnetic, and ultrasonic designs.

The turbine-type flowmeters simply convert the flow to the rotation of the rotor proportionally. The physical principle behind the electromagnetic flowmeter concept is electromagnetic induction. A magnetic field creates a potential difference that is proportional to the flow velocity and is sensed by electrodes. The ultrasonic flowmeter concept utilizes the Doppler effect, registering the difference in frequencies of ultrasound waves emitted along and against the direction of the flow. These types of flowmeters are applicable to different objects due to their different physical principles, although providing the same function.

The choice between these three types of flowmeters, whose design is elaborated and requires economic assessment, serves as the case study here. As these three types are designed to operate in different liquids, we treat them as different products. Thus, we compare the three designs not directly to each other, but to their existing analogs. Then the marginal benefit introduced by a new design is evaluated (in other words, how much cheaper the new design is). After these cost reduction estimates, the three target designs are compared to each other. Thus, the objective of our evaluation is to estimate what design type offers higher cost reduction to the market.

For the purpose of illustration, we use six commercially available solutions. Three of them represent 'invented designs in process', while the three others are assigned to be 'existing market products' for comparison. Their specifications are presented in rows 1-10 of Table 3. All the presented designs differ in the set of objects (liquids), lifetime, repair cycle, productivity, electricity consumption, as well as manufacturing and installation costs. Levelized function cost 
is calculated per one cubic meter of measured liquid. We use (6), because productivity is constant over time, but not the O\&M costs, for which we calculate the present value separately. The LFC calculation is reflected in rows 11-23 of Table 3 and includes the following steps:

1. Input estimation:

- Calculating annual productivity as the number of measured cubic meters per annum (row 12);

- Estimation of the O\&M costs and discounting them (row 18). The O\&M costs consist of electricity cost (with assumed electricity price 2 c.u./kWh) and repairing costs that occur in accordance with the repairing cycle for each device. All costs are discounted at a $10 \%$ discount rate.

- Calculating the initial cost (row 19) as a sum of manufacturing and installation costs. No discounting is needed, as this expense occurs in the initial period.

- Calculating the capital recovery factor, taking technology lifetime into account (row 21);

2. Calculating LFC in accordance with (6) (row 22);

3. Defining cost reduction as a difference in LFCs of the existing analog and the new design, divided by the LFC of the analog to get the percentage value (row 23).

The obtained levelized cost estimate in $c . u . /$ cubic meter shows that turbine flowmeters are the cheapest alternative if only clean water is to be measured, followed by the electromagnetic flowmeters that serve a broader set of liquids, concluding with ultrasonic ones that can be applied to any liquid. The overall picture looks reasonable, as the more objects are to be treated by the function, the more expensive the solution is. However, the fact that different designs can be applied to different sets of liquids makes the direct cost comparison biased. Therefore, we have compared each solution to the existing analog, checking how much value the new design delivers. 
The results demonstrate that the ultrasonic flowmeter design offers the highest cost reduction (50\%), followed by the turbine design (21\%), and ending with a minor achievement by the electro-magnetic design (1\%). With such estimations, the decision should be made in favor of the ultrasonic design, as it represents the highest cost reduction potential to the existing analog and thus the most profitable trade-off.

For further analytics and assistance in further design development, sensitivity analysis of its LFC to different parameters can be recommended. Here we present sensitivity analysis for the LFC of the 'winning' ultrasonic flowmeter. Figure 1 shows how levelized cost changes ( $y$ axis) with one by one change in the design parameters ( $x$ axis) from $-50 \%$ to $50 \%$ with $10 \%$ steps.

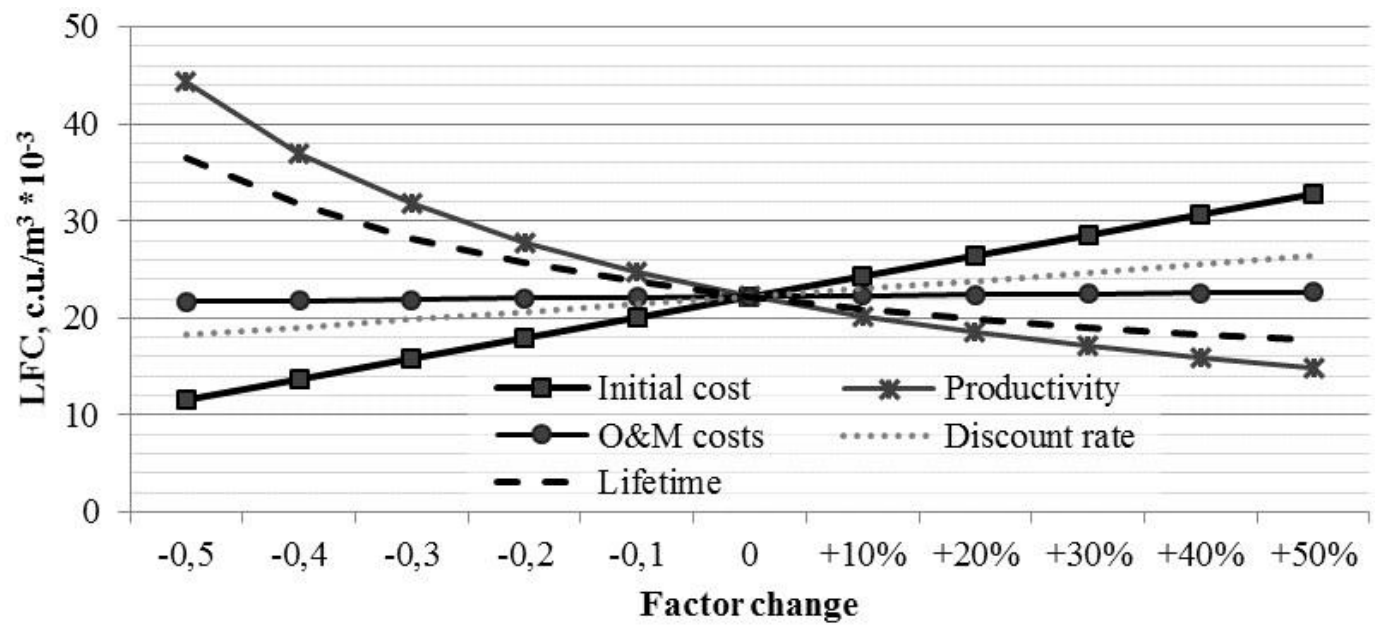

Figure 1 . LFC sensitivity analysis for ultrasonic design

As it can be seen in the graph, the initial cost cut has the biggest potential for the LFC reduction. The O\&M costs, being relatively low comparing to the initial cost, do not affect LFC much. The discount rate is of minor influence as well. Sensitivity to lifetime and productivity is similar, though with more amplitude for productivity, and it also offers some potential for LFC reduction. However, it is worth mentioning that the bigger these parameters, the smaller the marginal saving in LFC. Such sensitivity analysis provides an economic basis for the decision on which direction the further design development should take. 
To sum up, the LFC indicator can enhance decision-making in engineering with economic considerations, and it can be used in particular for choosing the most economically viable tradeoff and to support the roadmap of further design elaboration. 
Table 3. Calculation of LFC for three designs and their benchmarks

\begin{tabular}{|c|c|c|c|c|c|c|c|}
\hline \multicolumn{8}{|c|}{ Design specifications } \\
\hline 1 & Type & \multicolumn{2}{|l|}{ Electromagnetic } & \multicolumn{2}{|l|}{ Turbine } & \multicolumn{2}{|l|}{ Ultrasonic } \\
\hline 2 & Liquids & \multicolumn{2}{|c|}{ Water, salt water, dirty water } & \multicolumn{2}{|c|}{ Only clear water } & \multicolumn{2}{|l|}{ All liquids } \\
\hline 3 & Commercialization & new & existing & new & existing & new & existing \\
\hline 4 & Design & Piterflow RS50 & PREM & Okhta T50 & VSHN & Vzloyt MR & PortaFlow 220 \\
\hline 5 & Lifetime, hours & 80000 & 80000 & 100000 & 100000 & 75000 & 13250 \\
\hline 6 & Verification cycle, years & 4 & 4 & 5 & 6 & 2 & - \\
\hline 7 & Flow, $\mathrm{m}^{3} /$ hour & 36 & 36 & 30 & 50 & 35 & 800 \\
\hline 8 & Electricity consumption, $\mathrm{V}^{*} \mathrm{~A}$ & 6 & 5 & 0 & 0 & 12 & 19 \\
\hline 9 & Cost of meter, c.u. & 16150 & 16530 & 4240 & 10875 & 34800 & 418000 \\
\hline 10 & Cost of installation, c.u. & 3000 & 3000 & 1500 & 1500 & 1500 & 1500 \\
\hline \multicolumn{8}{|c|}{ LFC calculation } \\
\hline 11 & Lifetime, years & 9.1 & 9.1 & 11.4 & 11.4 & 8.6 & 1.5 \\
\hline 12 & Measured flow per year, $\mathrm{m}^{3}$ & 315360 & 315360 & 262800 & 438000 & 306600 & 7008000 \\
\hline
\end{tabular}




\begin{tabular}{|c|c|c|c|c|c|c|c|}
\hline 13 & Electricity consumption, $\mathrm{kWh} /$ year & 53 & 44 & 0 & 0 & 105 & 168 \\
\hline 14 & Electricity price, $c . u . / \mathrm{kWh}$ & 2 & & & & & \\
\hline 15 & Electricity cost, c.u./year & 105 & 88 & 0 & 0 & 210 & 337 \\
\hline 16 & Present value (PV) of electricity cost & 611 & 509 & 0 & 0 & 1173 & 452 \\
\hline 17 & PV of maintenance cost & 230 & 230 & 201 & 113 & 508 & 0 \\
\hline 18 & O\&M costs (PV), c.u. & 841 & 739 & 201 & 113 & 1681 & 452 \\
\hline 19 & Initial costs, c.u. & 19150 & 19530 & 5740 & 12375 & 36300 & 419500 \\
\hline 20 & Discount rate (real) & $10 \%$ & & & & & \\
\hline 21 & Capital recovery factor & $17 \%$ & $17 \%$ & $15 \%$ & $15 \%$ & $18 \%$ & $74 \%$ \\
\hline 22 & Levelized function cost (LFC), c.u. $/ \mathrm{m}^{3}$ & $10.9 * 10^{-3}$ & $11.1 * 10^{-3}$ & $3.4 * 10^{-3}$ & $4.3 * 10^{-3}$ & $22.2 * 10^{-3}$ & $44.6^{*} 10^{-3}$ \\
\hline 23 & Cost reduction & $1 \%$ & & $21 \%$ & & $50 \%$ & \\
\hline
\end{tabular}




\section{Discussion and conclusion}

Design evaluation from the economic point of view is crucial in the early stages of new product development. The earlier an engineer is able to evaluate the design from the economic perspective, the less effort is wasted on perfecting the ideas that are technologically attractive but not economically viable.

The paper presents a method for express economic evaluation of the design concept based on the levelized cost approach adopted from the power generation sector. Levelized function cost represents a single indicator of all life-cycle concept-related costs per a unit of performed function, reflecting also design productivity and lifetime. Thus, it is easy to use and interpret for engineers.

The proposed approach suits essentially the trend of focusing on function or service rather than on a device, material or object in new product design. The approach is illustrated by a case study of evaluating three flowmeter designs.

A known drawback of the levelized cost indicator in its original application area is possible variations driven by location differences (Borenstein 2011, 67-92). This includes local labor costs, access to fuel transportation and electricity transmission, which contribute to operational and initial costs, not to mention climate conditions for renewable energy technologies, which affect the electricity output strongly. However, this disadvantage is hardly inherited to the design assessment, except in technology cases with similar dependence on the location. Nevertheless, a new limitation of the approach arises from its application to design evaluation. Since the conceptual design stage lacks details on the concept even from the engineering side, assumptions made regarding its costs are essentially vague and can bias the resulting estimate. For this reason, cost assumptions should be made carefully. To improve the reliability of the estimation, the effect of assumption variation should be captured with e.g. sensitivity analysis as illustrated in this paper, or with soft computing -based techniques. 
A separate attention deserves discussion of the LFC in the context of MCDM. As shown in numerous reviews, often chosen criteria for MCDM are constituted of quality (failure rate), production performance or efficiency, lifetime, maintenance etc. (Ho, Xu, and Dey 2010, 1624). In case, when all these criteria can be reflected in LFC formula, we recommend direct assessing cost of function delivered to a customer based on known relationship between criteria and the outcome, instead of conducting valuation with MCDM, where set weights or estimate aggregation algorithms may not necessarily reflect the reality in the best way. However, when important to consider criteria cannot be captured by the LFC estimate, MCDM are better choice, nevertheless, instead of multiple cost criteria, one aggregated LFC can clarify and simplify the decision problem. In other words, LFC can be used as a standalone indicator or can also be integrated in multi criteria decision making approaches and existing evaluation roadmaps.

Further research should consider the integration of LFC into systematic approaches to design development, like value engineering and quality management systems. Enhancing the LFC estimation with fuzzy set theory -based techniques will increase the reliability of the method by capturing possible imprecision in target design specifications and expected performance. It is also supposed to integrate LFC into design software to provide engineers with a practical tool for economic evaluation of new ideas.

\section{Acknowledgement}

The authors would like to acknowledge the support by Fortum Foundation (grant No. 201700063), the Finnish Strategic Research Council project "Manufacturing 4.0" (grant No. 313396), and TEKES, the Finnish Funding Agency for Innovation, and its program FiDiPro. We would also like to acknowledge the input of Prof. Mikael Collan from LUT School of Business and Management. He provoked and inspired the authors to bridge design and evaluation methods. 
Altshuller, Genrich Saulovich, and Rafael Borisovich Shapiro. 1956. Psychology of inventive creativity. Issues of Psychology $6: 37-49$.

Besharati, B., Shapour Azarm, and PK Kannan. 2006. A decision support system for product design selection: A generalized purchase modeling approach. Decision Support Systems 42 (1): 333-50.

Bloomberg New Energy Finance. The cost landscape of solar and wind. 2015 [cited October 12 2015]. Available from http://www.senate.mn/committees/20152016/3058_Committee_on_Environment_and_Energy/20151_BNEF_presentation_final.pdf.

Borenstein, Severin. 2011. The private and public economics of renewable electricity generation. Journal of Economic Perspectives 26 (1): 67-92.

Branker, Kadra, MJM Pathak, and Joshua M. Pearce. 2011. A review of solar photovoltaic levelized cost of electricity. Renewable and Sustainable Energy Reviews 15 (9): 4470-82.

Breyer, Christian, and Alexander Gerlach. 2013. Global overview on grid-parity. Progress in Photovoltaics: Research and Applications 21 (1): 121-36.

Campbell, Matt, P. Aschenbrenner, J. Blunden, E. Smeloff, and S. Wright. 2008. The drivers of the levelized cost of electricity for utility-scale photovoltaics. White Paper: SunPower Corporation.

Chechurin, Leonid, and Yuri Borgianni. 2016. Understanding TRIZ through the review of top cited publications. Computers in Industry 82 : 119-34.

Dong, Andy, Dan Lovallo, and Ronny Mounarath. 2015. The effect of abductive reasoning on concept selection decisions. Design Studies 37 : 37-58.

Fisher, Irving. 1907. The rate of interest: Its nature, determination and relation to economic phenomenaMacmillan.

Fuller, S. K., and Petersen, S. R. Life-cycle costing manual for the federal energy management program. 1995 [cited December 3 2015]. Available from http://www.nist.gov/customcf/get_pdf.cfm?pub_id=907459.

Gerasimov, V., V. Kalish, A. Kuzmin, and SS Litvin. 1991. Basics of function-cost analysis approach. Guidlines (in Russian).Moscow: Moscow, Inform-FSA: 40.

Graham, John R., and Campbell R. Harvey. 2001. The theory and practice of corporate finance: Evidence from the field. Journal of Financial Economics 60 (2-3) (5): 187-243.

Hernández-Moro, J., and JM Martínez-Duart. 2013. Analytical model for solar PV and CSP electricity costs: Present LCOE values and their future evolution. Renewable and Sustainable Energy Reviews 20 : 119-32. 
Hirtz, Julie M., Robert B. Stone, S. Szykman, DA McAdams, and Kristin L. Wood. 2001. Evolving a functional basis for engineering design. Paper presented at Proceedings of the ASME Design Engineering Technical Conference: DETC2001, Pittsburgh, PA, .

Ho, William, Xiaowei Xu, and Prasanta K. Dey. 2010. Multi-criteria decision making approaches for supplier evaluation and selection: A literature review. European Journal of Operational Research 202 (1): 16-24.

Ilevbare, Imoh M., David Probert, and Robert Phaal. 2013. A review of TRIZ, and its benefits and challenges in practice. Technovation 33 (2-3) (0): 30-7.

Jones, Thomas W., and J. David Smith. 1982. An historical perspective of net present value and equivalent annual cost. The Accounting Historians Journal: 103-10.

Khastagir, Anirban, and Niranjali Jayasuriya. 2011. Investment evaluation of rainwater tanks. Water Resources Management 25 (14): 3769-84.

Magrab, Edward B., Satyandra K. Gupta, F. Patrick McCluskey, and Peter Sandborn. 2009. Integrated product and process design and development: The product realization processCRC Press.

Malen, Donald E. 1996. Decision making in preliminary product design: Combining economic and quality considerations. The Engineering Economist 41 (2): 105-22.

Marx, Karl. 1894. Capital: A critique of political economy, vol. III. the process of capitalist production as a whole [Das Kapital, Kritik der politischen Ökonomie]. Trans. Ernest Untermann, ed. Frederick Engels. Chicago: Charles H. Kerr and Co.

Miles, Lawrence D., and Hans Hermann Boehm. 1967. Value engineeringVerlag Moderne Industrie.

Moehrle, Martin G. 2005. How combinations of TRIZ tools are used in companies-results of a cluster analysis. $R \& D$ Management 35 (3): 285-96.

Nikander, Jan B., Lassi A. Liikkanen, and Miko Laakso. 2014. The preference effect in design concept evaluation. Design Studies 35 (5): 473-99.

Ogden, Kimberly L., Gregory E. Ogden, John L. Hanners, and Pat J. Unkefer. 1996. Remediation of low-level mixed waste: Cellulose-based materials and plutonium. Journal of Hazardous Materials 51 (1): 115-30.

Okudan, Gul E., and Shafin Tauhid. 2008. Concept selection methods-a literature review from 1980 to 2008. International Journal of Design Engineering 1 (3): 243-77.

Ouyang, Xiaoling, and Boqiang Lin. 2014. Levelized cost of electricity (LCOE) of renewable energies and required subsidies in china. Energy Policy 70 : 64-73.

Park, Yongtae, and Gwangman Park. 2004. A new method for technology valuation in monetary value: Procedure and application. Technovation 24 (5) (5): 387-94.

Pugh, Stuart, and Don Clausing. 1996. Creating innovtive products using total design: The living legacy of stuart pughAddison-Wesley Longman Publishing Co., Inc. 
Reichelstein, Stefan, and Anna Rohlfing. 2014. Levelized product cost: Concept and decision relevance. The Accounting Review.

Ryan, Patricia A., and Glenn P. Ryan. 2002. Capital budgeting practices of the fortune 1000: How have things changed. Journal of Business and Management 8 (4): 355-64.

SAVE International. Value methodology standard. 2015 [cited December 3 2015]. Available from http://www.value-eng.org/pdf_docs/monographs/vmstd.pdf.

Short, Walter, Daniel J. Packey, and Thomas Holt. 2005. A manual for the economic evaluation of energy efficiency and renewable energy technologiesUniversity Press of the Pacific.

Suh, Nam P. 1990. The principles of designOxford University Press on Demand.

Toh, Christine A., and Scarlett R. Miller. 2015. How engineering teams select design concepts: A view through the lens of creativity. Design Studies 38 : 111-38.

US Energy Information Administration. Levelized cost and levelized avoided cost of new generation resources in the annual energy outlook 2015. 2015 [cited October 12 2015]. Available from http://www.eia.gov/forecasts/aeo/pdf/electricity_generation.pdf.

Wallace, Ken, and Stuart Burgess. 1995. Methods and tools for decision making in engineering design. Design Studies 16 (4) (10): 429-46.

World Energy Council. World energy perspective. cost of energy technologies. 2013 [cited October 12 2015]. Available from https://www.worldenergy.org/wpcontent/uploads/2013/09/WEC_J1143_CostofTECHNOLOGIES_021013_WEB_Final.p df.

Younker, Del. 2003. Value engineering: Analysis and methodology. Vol. 30CRC Press. 